Article

\title{
Flavonoids Extraction Kinetics, Antimicrobial Activity and Radical Scavenging Potential of Bulgarian Woundwort (Solidago virgaurea L.)
}

\author{
Zvezdelina Yaneva ${ }^{1, *(D)}$, Evgeni Simeonov ${ }^{2}$, Nikolina Rusenova ${ }^{3}\left(\mathbb{D}\right.$, Donika Ivanova ${ }^{1,4}$, Galina Nikolova ${ }^{4}$, \\ Yanka Karamalakova ${ }^{4}$, Chavdar Chilev ${ }^{2}$ and Georgi Beev ${ }^{5}$
}

1 Chemistry Unit, Department of Pharmacology, Animal Physiology, Biochemistry and Chemistry, Faculty of Veterinary Medicine, Trakia University, Students Campus, 6000 Stara Zagora, Bulgaria; donika_georgiewa@abv.bg

2 Department of Chemical Engineering, Faculty of Chemical and System Engineering, University of Chemical Technology and Metallurgy, 1756 Sofia, Bulgaria; evgeni@uctm.edu (E.S.); cchilev@abv.bg (C.C.)

3 Veterinary Microbiology Unit, Department of Veterinary Microbiology, Infectious and Parasitic Diseases, Faculty of Veterinary Medicine, Trakia University, Students Campus, 6000 Stara Zagora, Bulgaria; n_v_n_v@abv.bg

4 Department of Chemistry and Biochemistry, Faculty of Medicine, Trakia University, 11 Armeiska Str., 6000 Stara Zagora, Bulgaria; galina.nikolova@trakia-uni.bg (G.N.); yanka.karamalakova@trakia-uni.bg (Y.K.)

5 Department of Biochemistry, Microbiology and Physics, Faculty of Agriculture, Trakia University, Students Campus, 6000 Stara Zagora, Bulgaria; gbeev@abv.bg

* Correspondence: zvezdelina.yaneva@trakia-uni.bg; Tel.: +359-898-399-203

\section{check for}

updates

Citation: Yaneva, Z.; Simeonov, E.; Rusenova, N.; Ivanova, D.; Nikolova,

G.; Karamalakova, Y.; Chilev, C.; Beev,

G. Flavonoids Extraction Kinetics,

Antimicrobial Activity and Radical

Scavenging Potential of Bulgarian

Woundwort (Solidago virgaurea L.).

Separations 2022, 9, 27. https://

doi.org/10.3390/separations 9020027

Academic Editor: Paraskevas

D. Tzanavaras

Received: 28 December 2021

Accepted: 18 January 2022

Published: 21 January 2022

Publisher's Note: MDPI stays neutral with regard to jurisdictional claims in published maps and institutional affiliations.

Copyright: () 2022 by the authors. Licensee MDPI, Basel, Switzerland. This article is an open access article distributed under the terms and conditions of the Creative Commons Attribution (CC BY) license (https:// creativecommons.org/licenses/by/ $4.0 /)$.

\begin{abstract}
The medicinal plant woundwort (Solidago virgaurea L.) characterizes by diuretic, antimutagenic, anti-inflammatory activity and it has been applied for urinary tract, nephrolithiasis and prostate disorders treatment. The aim of the present study was to analyze the extraction kinetics of catechin, epigallocatechin and quercetin from Bulgarian woundwort extracts, to assess the antibacterial potential of the medicinal plant extracts against four bacterial strains (Staphylococcus aureus ATCC25923, Escherichia coli ATCC 25922, Pseudomonas aeruginosa ATCC 27853 and Bacillus cereus), their antioxidant capacity and radical scavenging potential. The concentrations of the flavonoids in the extracts obtained at different extraction conditions (solvent, temperature, extraction time) were determined by newly-developed by the scientific team RP-HPLC-PDA methodologies. The agar well diffusion method was applied to evaluate the antibacterial activity of the plant extracts. The $70 \%$ EtOH extracts at $20{ }^{\circ} \mathrm{C}$ displayed significantly higher antibacterial activity against the foodborne pathogenic bacteria S. aureus and P. aeruginosa as compared to the $70 \%$ and $98 \% \mathrm{EtOH}$ extracts at $30{ }^{\circ} \mathrm{C}$ and $20^{\circ} \mathrm{C}$, respectively. The medicinal plant exhibited satisfactory antioxidant potential and radical-scavenging activity.
\end{abstract}

Keywords: woundwort; catechin; epigallocatechin; quercetin; antimicrobial activity; antioxidant potential

\section{Introduction}

Modern health conscious lifestyle has been taking advantage of medicines, food additives and dietary supplements of natural origin, such as plant extracts containing high amounts of important groups of secondary metabolites. The latter including flavonoids, phenolic acids, quinones, tannins, etc., possess diverse structures and functions and have been putatively recognized to exhibit various biological activities: antioxidant, antimicrobial, antiproliferative, anti-inflammatory, antidiabetic, etc. [1-3].

Flavonoids constitute a large class of natural phenolic compounds which are plants bioactive secondary metabolites. Modern scientific studies report their immunomodulatory, anti-inflammatory, hepatoprotective, antiviral and anticancer activities [4]. These effects 
emanate from the potential of the polyphenolic compounds to reduce oxidative stress, inhibit the oxidation of lipoproteins and vasodilation activity $[5,6]$.

The precise elicitation of the mechanisms of the physiological activities of medicinal plant extracts requires detailed qualitative and quantitative analyses of these multicomponent systems, so that to evaluate the individual biopotency of the components and to reveal their biochemical pathways and therapeutic potential.

With respect to the growing risk of antibiotic resistance and based on novel scientific data that medicinal plants flavonoids have been recognized as promising antimicrobial agents [7], recent scientific studies have been directed towards in-depth investigations in this field of medicinal chemistry and biomedicine. Modern scientific literature reports antibacterial activity of various plant extracts applying water and numerous organic solvents (acetone, ethanol, methanol, ethyl acetate) as extracting agents [8]. Gonelimali et al. [9] reported that roselle (Hibiscus sabdariffa), rosemary (Rosmarinus officinalis), clove (Syzygium aromaticum), and thyme (Thymus vulgaris) water and ethanol extracts displayed antibacterial and antifungal activities against Gram positive and Gram negative bacterial strains. These findings were substantiated by the decline in cytoplasmic $\mathrm{pH}$ and cell membrane hyperpolarization [9].

Another study demonstrated high antibacterial potential of $O$. corniculata extract against Escherichia coli, Salmonella Typhi, MDR Salmonella Typhi, Klebsiella pneumoniae, and Citrobacter koseri. and satisfactory activity of Plumbago indica [10], Artemisia vulgaris, Cinnamomum tamala, and Ageratina adenophora methanolic extracts against Staphylococcus aureus [11]. The investigations of Owusu et al. [12] demonstrated antimicrobial activity of water and ethanol extracts of several African Sub-Saharan medicinal plants against MD-R bacterial pathogens that were previously isolated from post-operative wounds.

Therapies applying antioxidant agents have been suggested as state-of-the-art approaches to mitigate diseases associated with oxidative stress. Antioxidants are proposed to exert versatile and multitargeted mechanisms that are associated with either oxidative homeostasis restoration or free radical accumulation. Plant-derived phenolics and flavonoids in medicinal plants behave as strong free-radical scavengers that prevent the cell damage caused by oxidative stress [13]. In this respect, significant in vitro and in vivo antioxidant potential of butanol extract from Ephedra alte in a concentration-dependent manner were reported by Al-Trad et al. [14]. The water and methanol extracts of P. thonning $i$ displayed satisfactory in vitro antilipid peroxidation potential, DPPH radical scavenging activity, and ferric reducing power efficiency [15]. The study of Zagórska-Dziok et al. [16] demonstrated the potential of M. sativa L. extracts to inhibit free radicals on the external cell environment as well as to reduce intracellular reactive oxygen species level, thus contributing to intercellular oxidative stress reduction.

European woundwort (Solidago virgaurea L., Amphiraphis leiocarpa, Amphiraphis pubescens, Dectis decurrens Raf., Doria virgaurea Scop.) is a representative of the Asteraceae family. In Bulgaria, the medicinal plant grows all around the country: in wetlands, low mountain regions, dry grassland, brush woods, from 500 to $2600 \mathrm{~m}$ above sea level. The herb characterizes by versatile bioactivities including cytotoxic, antitumor, anti-inflammatory, analgesic, diuretic, cardioprotective, etc properties [17]. According to scientific literature its pharmacological activity is due to the presence of a number of biologically active substances, among which flavonoids (catechin, epigallocatechin, naringenin, quercetin, genstein, kaempferol, etc.) are considered the most essential [18].

The aim of the present study was to analyze the extraction kinetics of catechin, epigallocatechin and quercetin from Bulgarian woundwort extracts, to assess the antibacterial potential of the medicinal plant extracts against four bacterial strains (Staphylococcus aureus ATCC25923, Escherichia coli ATCC 25922, Pseudomonas aeruginosa ATCC 27853 and Bacillus cereus), their antioxidant capacity and radical scavenging potential. 


\section{Materials and Methods}

\subsection{Chemicals}

The reagents methanol $(\mathrm{MeOH}, \geq 99.9 \%)$, ethanol (EtOH, p.a. $\geq 99.8 \%)$, acetonitrile (ACN, $\geq 99.8 \%$ ), orthophosphoric acid $\left(\mathrm{H}_{3} \mathrm{PO}_{4}, 85 \%\right)$, L-ascorbic acid, $\mathrm{CH}_{3} \mathrm{COOH}, \mathrm{NaOH}$ (p.a., HPLC) and DPPH (2,2-diphenyl-1-picrylhydrazyl) were supplied by Sigma-Aldrich (St. Louis, MA, USA). Milli-Q water was used to prepare the mobile phase for the HPLC analyses. The calibration curves of the three analyzed flavonoids were obtained by the use of the following standard compounds: (+)-catechin hydrate ( $\geq 96.0 \%$, HPLC), (-)epigallocatechin (analytical standard), quercetin hydrate ( $\geq 95 \%$, HPLC) (Sigma Aldrich, MA, USA) (Supplementary Figure S1).

\subsection{Plant Material}

Solidago virgaurea L. aerial parts (leaves and inflorescences) were harvested at full flowering stage from Sredna gora Region, Bulgaria, during the period June-July, 2018. The raw material was dried in the shade, at a temperature of $20-30{ }^{\circ} \mathrm{C}$. The water content of woundwort after drying was below 5\%. The air-dried plant material was mechanically ground with a laboratory mill to obtain a homogenous powder

\subsection{Extraction Procedure}

The ground raw material was placed in a stirred batch extraction reactor at liquid/solid ratio $\xi=0.03 \mathrm{~m}^{3} / \mathrm{kg}$ and filled with the appropriate solvent by heating in a thermostatic water bath with constant stirring. The agitation rate was $n=4 \mathrm{~s}^{-1}$ to ensure internal diffusion mode. The temperature during the experiments in the thermostat was maintained by means of a contact thermometer and an external cycle with cooling water. After the set extraction time has elapsed, the samples were carefully filtered.

Four series of woundwort extracts were prepared and analyzed: Series 1 -solvent $70 \% \mathrm{EtOH}$, extraction temperature $\mathrm{T}=20^{\circ} \mathrm{C}$ ( samples designated as $\left.\mathrm{S}^{\prime}-\mathrm{S}^{\prime}\right)$; Series 2 solvent $70 \% \mathrm{EtOH}$, extraction temperature $\mathrm{T}=30^{\circ} \mathrm{C}$ (samples designated as S1-S9); Series 3 - solvent $98 \% \mathrm{EtOH}$, extraction temperature $\mathrm{T}=20{ }^{\circ} \mathrm{C}$ (samples designated as $\mathrm{S}^{\prime \prime}-\mathrm{S} 9^{\prime \prime}$ ); Series 4 -solvent $\mathrm{H}_{2} \mathrm{O}$, extraction temperature $\mathrm{T}=20^{\circ} \mathrm{C}\left(\mathrm{S}^{\prime \prime \prime}-\mathrm{S} 9^{\prime \prime \prime}\right)$. To study the extraction kinetics nine samples from each series were collected at extraction times 5, 10, 15, 20, 30, 60, 90, 120, 140 and $160 \mathrm{~min}$, respectively.

\subsection{RP-HPLC-PDA Analyses}

The quantitative analyses of the flavonoids (catechin, epigallocatechin, quercetin) contents in the four woundwort extract series were determined by newly developed by the authors liquid chromatographic techniques specific for each of the bioactive substances analyzed which were described elsewhere $[19,20]$. In brief, the HPLC system consisted of a Hypersil BDS C18 column $(5 \mu \mathrm{M}, 4.6 \times 150 \mathrm{~mm})$, a Surveyor LC Pump Plus pump, a PDA detector, and an Autosampler Plus autosampler (Thermo Fisher Scientific, Waltham, MA, USA). All extracts were preliminary filtered through $0.45 \mu \mathrm{m}$ syringe filters (Hach Lange, Düsseldorf, Germany). The sample volume was $20 \mu \mathrm{L}$. The specific chromatographic conditions are summarized in Table 1.

All chromatographic analyses were performed in triplicate and the mean values of the reported concentrations were presented. The experimental HPLC chromatograms were analyzed with ChromQuestTM chromatography workstation software system Version 4.2 (Thermo Electron Corporation, Waltham, MA, USA). The data from the chromatographic analyses allowed the study of the extraction process kinetics. 
Table 1. RP-HPLC-PDA conditions for the quantitative flavonoids profile of woundwort extracts.

\begin{tabular}{|c|c|c|c|}
\hline Flavonoid & Quercetin & Catechin & Epigallocatechin \\
\hline Mobile phase & \multicolumn{3}{|c|}{ MeOH:AcCN:H ${ }_{2} \mathrm{O}=40: 15: 45(v / v / v)\left(+1 \% \mathrm{CH}_{3} \mathrm{COOH}\right)$} \\
\hline Maximum wavelength & $\begin{array}{c}\lambda=360 \mathrm{~nm}-\text { for solvents water, } \\
70 \% \mathrm{EtOH} \text { and } 98 \% \mathrm{EtOH}\end{array}$ & $\begin{array}{r}\lambda=26 \\
\lambda=325 \mathrm{~nm}-\text { for }\end{array}$ & $\begin{array}{l}\text { ent water; } \\
\text { tOH and } 98 \% \mathrm{EtOH}\end{array}$ \\
\hline Flow rate & $0.5 \mathrm{~mL} / \mathrm{min}$ & & \\
\hline Precolumn derivatization & + & & \\
\hline Column temperature & $30{ }^{\circ} \mathrm{C}$ & & \\
\hline Detection time & $\mathrm{t}=5.8 \mathrm{~min}$ & $\mathrm{t}=4.3 \mathrm{~min}$ & $\mathrm{t}=3.5 \mathrm{~min}$ \\
\hline
\end{tabular}

\subsection{FT-IR Analyses}

The FT-IR spectra of the liquid extracts were obtained with the $\mathrm{CaF}_{2}$ plate technique in the range $800-4000 \mathrm{~cm}^{-1}$, while the spectra of the solid powdered standard flavonoids with the $\mathrm{KBr}$ disc technique in the range $400-4000 \mathrm{~cm}^{-1}$, using a TENSOR 37 Bruker FTIR spectrometer (Bruker Optik GmbH, Ettlingen, Germany). The spectra in the range from 4000 to $400 \mathrm{~cm}^{-1}$ were the average of 64 scans at a resolution of $2 \mathrm{~cm}^{-1}$. The ATR signal was transformed to transmittance and the obtained spectra were normalized after the baseline correction.

\subsection{Antimicrobial Screening}

Agar well diffusion method was used to screen the antibacterial activity of the woundwort extracts against Staphylococcus aureus ATCC 25923, Escherichia coli ATCC 25922, Pseudomonas aeruginosa ATCC 27853 and the clinical isolate-Bacillus cereus. In brief, for measuring of antibacterial activity, inoculums were prepared in saline corresponding to 0.5 of the McFarland standard $\left(1.5 \times 10^{8} \mathrm{CFU} / \mathrm{mL}\right)$ from $24 \mathrm{~h}$ bacterial colonies incubated on trypticase soy agar (Himedia, Mumbai, India) supplemented with $5 \%$ defibrinated sheep blood. Twenty $\mathrm{mL}$ of molted Mueller Hinton agar (Himedia, Mumbai, India) was added to each Petri dish. A sterile $6 \mathrm{~mm}$ cork borer was used for the formation of the wells after the inoculum was pre-applictaed with a sterile cotton swab. $100 \mu \mathrm{L}$ of the extracts in $\mathrm{EtOH}(70 \%$ and $98 \%$ ) were added to the wells. A positive control with gentamicin at a concentration of $12.5 \mu \mathrm{g} / \mathrm{mL}$ and a negative one with ethanol ( $70 \%$ and $98 \%)$ were performed. The plates were incubated at $37^{\circ} \mathrm{C}$ for $24 \mathrm{~h}$ under aerobic conditions. Antimicrobial activity was detected by measuring the inhibition zone (IZ, $\mathrm{mm}$ ) (including the wells diameter) that appeared after the incubation period [21].

\subsection{In Vitro Antioxidant Activity}

To measure the antioxidant activity of the woundwort extracts, four methods with different mechanisms of action were applied: (i) DPPH Radical Scavenging Assay: The DPPH (2,2-diphenyl-1-picrylhydrazyl) scavenging activity according to Cuendet et al. [22] with slight modifications [23]; (ii) ABTS ${ }^{\bullet+}$ assay: The radical-scavenging activity of $S$. virgaurea L. extracts against 2,2-azinobis (3-ethylbenzothiazoline-6-sulfonic acid) was determined by Re et al. [24] with modifications by Adhikari et al. [25]; (iii) Ferric Reducing Power/electron donation (FRAP) assay: The FRAP assay was performed according to a previously reported method with a slight modification [26,27]; (iv) NO assay: The presence a stable oxidized product as a rsults of nitric oxide ion scavenging of the extracts $(50 \mu \mathrm{g} / \mathrm{mL})$ was performed according to the methodology of Shirwaikar et al. [28] with modification by Karamalakova et al. [29].

\subsection{UV-B Treatment}

Two of the ethanol extracts with the highest flavonoid concentrations from Series 1 and 2 were irradiated at a distance from the light source of 25 to $35 \mathrm{~cm}$ and a quartz cover was applied to permit UV transparency and to halt evaporation of the extract and keeping it 
in a horizontal position on UV-B-vis Transilluminator 4000 (Stratagene, La Jolla, CA, USA) (emitting between $290 \mathrm{~nm}$ and $320 \mathrm{~nm}$; peak $309 \mathrm{~nm}$ ). The experimental UV-B intensity was calibrated in each experiment. To assess the dose response value of the UV-B radiation effect, the samples were subjected to UV-B irradiation within the range from 0 to $12 \mathrm{~kJ} / \mathrm{m}^{2}$ without visible ray, at less than 291-293 K. The energy of UV-B irradiation was controlled with 120 min exposure time. Dark, fresh air and $46 \%$ relative humidity was circulated in the illuminator throughout the irradiation course.

To study the effect of UV-B radiation on the antioxidant and free radical scavenging activity, the samples were stored at $293 \mathrm{~K}$ in the dry air/dark and re-examined for $24 \mathrm{~h}$ at the 2 nd month of post irradiation.

\subsection{Statistical Analysis}

The data obtained from the HPLC, kinetics extraction, antimicrobial and in vitro antioxidant activity studies were expressed as means \pm standard deviation (SD) from three repetitions with Statistica 7.1, StaSoft Inc. (Tulsa, OK, USA), one-way ANOVA. The statistical significance was determined by Student's $t$-test as the post-hoc test. A value of $p<0.05$ was considered as statistically significant. The kinetic data were expressed as the average of three independent measurements, which were processed using the computer programs Origin 6.1 (OriginLab Corporation, Northampton, MA, USA) and Microsoft Excel 2010 (Microsoft Corporation, WA, USA).

\section{Results and Discussion}

\subsection{RP-HPLC Analyses of Woundwort Extracts and Extraction Kinetics Curves}

The concentrations of catechin (CAT), epigallocatechin (EPI) and quercetin (QUER) in the four extracts series were determined by RP-HPLC on the basis of the standard calibration curves of the three flavonoids. The volume of all samples used in the RPHPLC assays was $1.5 \mathrm{~mL}$. The RP-HPLC chromatograms of the three biologically active polyphenols characterized with well resolved peaks presented in Figure 1.

The kinetics of the extraction process is influenced by numerous factors such as temperature, solvent type, solute and solvent diffusion capacity, etc. It consists of the release of biologically active compounds from porous or cellular plant matrices into the solvent through mass transfer [30-32].

The selection and application of water, $70 \% \mathrm{EtOH}$ and $96 \% \mathrm{EtOH}$ as solvents for the extraction of the flavonoids catechin, epigallocatechin and quercetin, on the one hand, was substantiated by the proven efficiency of these extracting agents as reported by novel scientific investigations. According to Koch et al. [33] polyphenols the extraction of polyphenols from green tea was the most efficient with ethanol and water and the lowest with ethyl acetate. The higher efficiency of ethanol and methanol as compared to that of other organic solvents such as acetone and acetonitrile was reported by Vuong et al. [34], while the study of Tsai and Chen [35] undoubtedly prove the highest recovery potential of $70 \% \mathrm{EtOH}$ as compared to $30 \%$ and $50 \%$ solutions.

On the other hand, ethanol is characterized with significantly lower toxicity as compared to other organic solvents such as methanol, chloroform, ethyl acetate, etc., applied as extracting agents, which is of utmost significance for the preparation of herbal extracts intended for medical purposes.

The main factors affecting solid-liquid extraction of valuable compounds from plant materials include extraction temperature, type and concentration of the solvents and contact time between the solid phase and the extraction agent. The assessment of the influence of these factors on the kinetics of the extraction process allows the optimization of the process and serves as a powerful tool for the simulation, design, and control of the extraction process. 


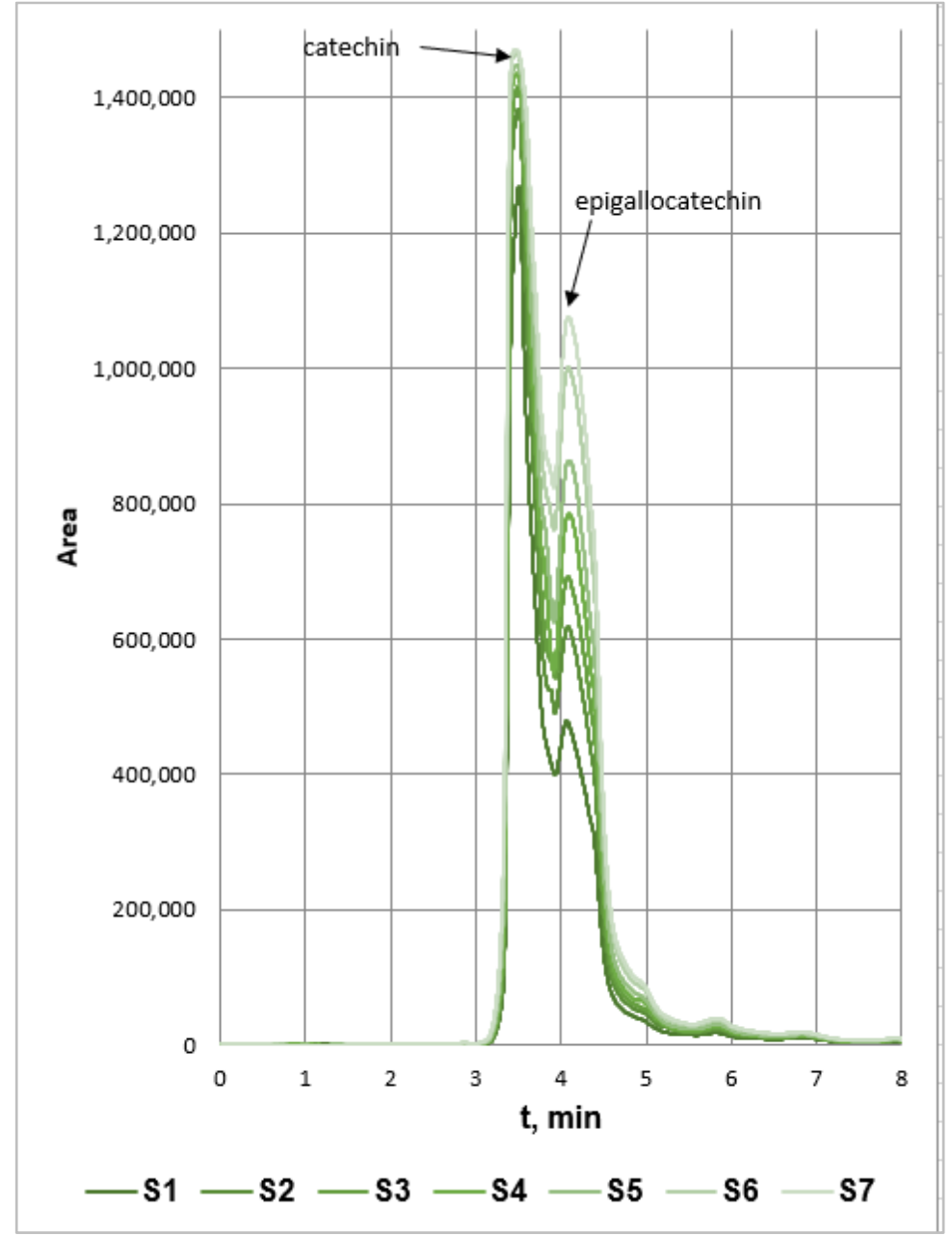

(A)

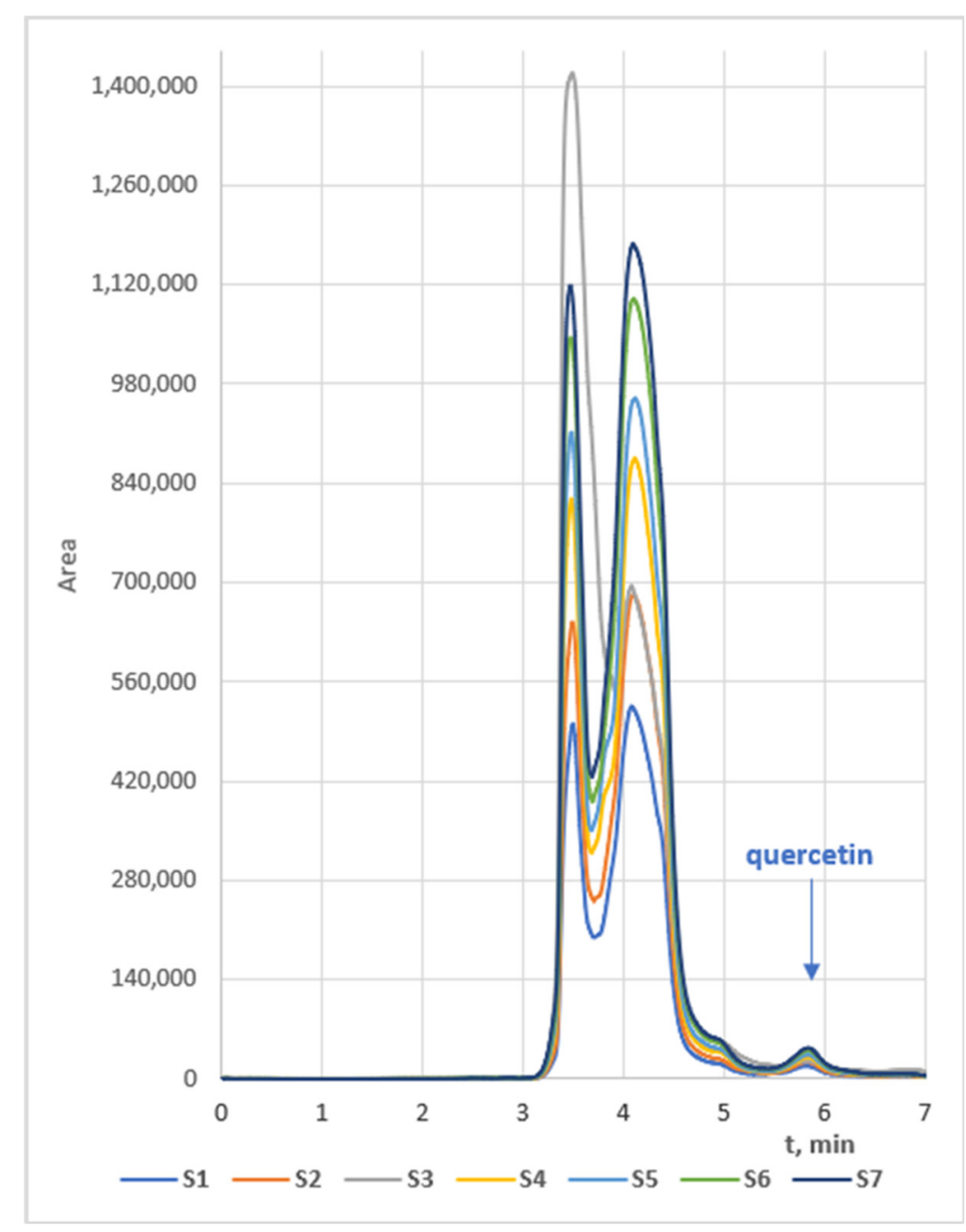

(B)

Figure 1. RP-HPLC spectra of: (A). catechin (detection time $4.3 \mathrm{~min}$ ) and epigallocatechin (detection time $3.5 \mathrm{~min}$ ), (B). quercetin (detection time 5.8 min) in the samples from Series 1 woundwort extracts. 
The extraction kinetics curves of the samples from the four series are displayed in Figure 2A-D. Obviously, the concentrations of catechin in the water extracts series prevailed that of epigallocatechin. This aberration of the flavonoids contents ratio could be subjected to the lower solubility of epigallocatechin in water $(\approx 5.0 \mathrm{mg} / \mathrm{mL})$ as compared to that of catechin $(\approx 7.6 \mathrm{mg} / \mathrm{mL})$. Besides, the maximum measured concentration of quercetin in the water extracts was approximately $20 \%$ lower than that in the $70 \% \mathrm{EtOH}$ extracts. The probable reason could also be associated with the low water solubility of the flavanone which accounts to $2.15 \mu \mathrm{g} / \mathrm{mL}$ [32]. From another aspect, the fact that quercetin concentration in the water extracts surpassed the water solubility of the anhydrous bioactive compound could be substantiated by the fact that the water extracts were turbid even after filtration (which imposed precolumn derivatization during the HPLC analyses) probably containing colloidal particles with insolubilized flavonoids that were dissolved in the $\mathrm{MeOH}$ containing mobile phase. Besides, the liquid/solid ratio of $\xi=0.03 \mathrm{~m}^{3} / \mathrm{kg}$ of the extraction processes is a testament for highly concentrated extracts.

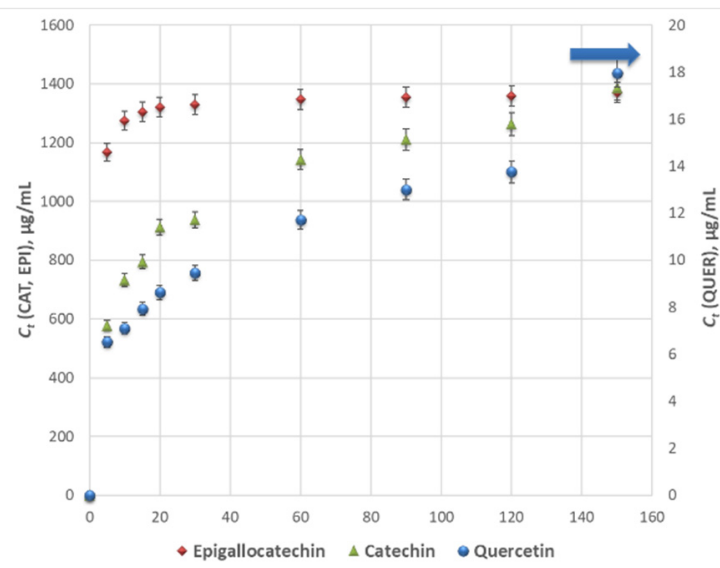

(A)

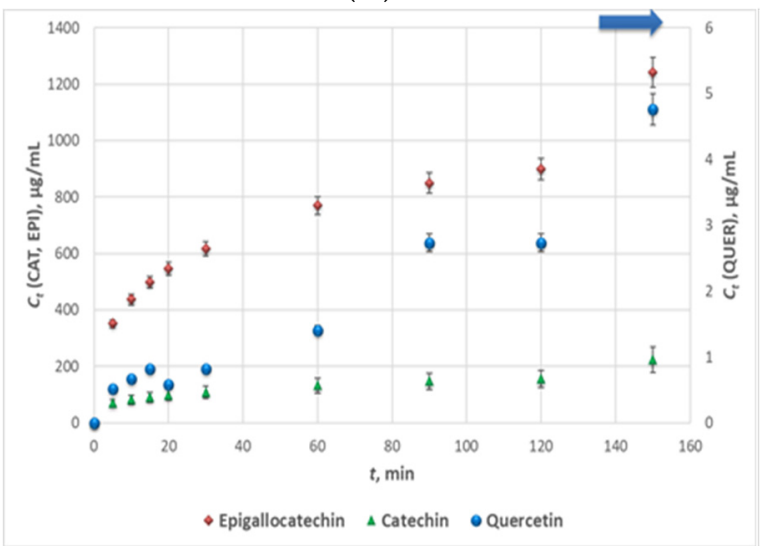

(C)

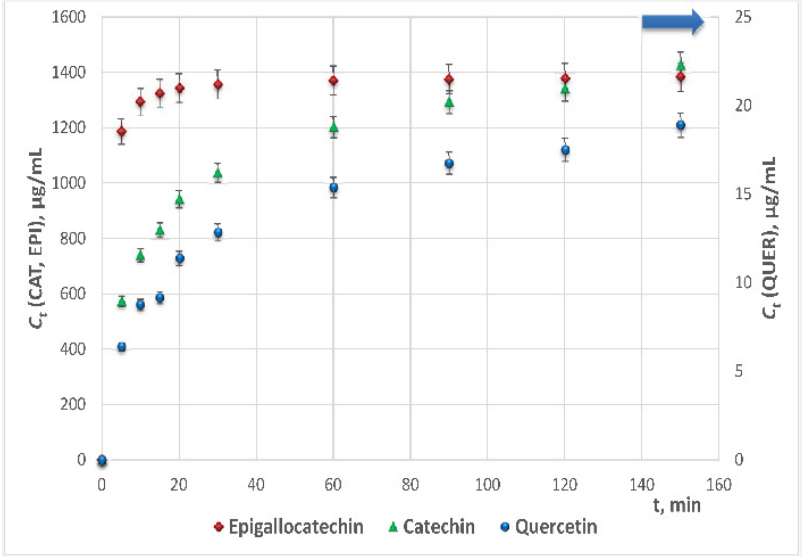

(B)

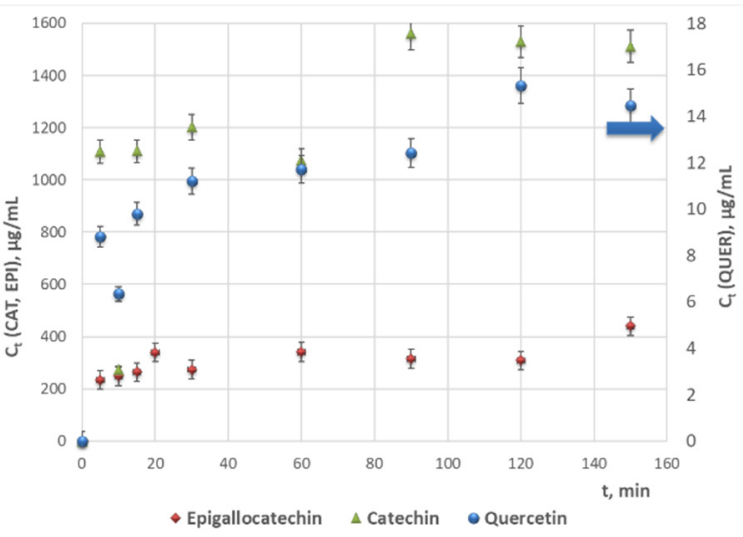

(D)

Figure 2. Extraction kinetics curves of woundwort samples from: (A). Series 1; (B). Series 2; (C). Series 3, and (D). Series 4, (CAT—catechin; EPI—epigallocatechin; QUER—quercetin).

The highest flavonoids concentrations in all studied extracts were registered at $160 \mathrm{~min}$ extraction time. The samples from Series 2 characterized with the highest average quercetin and epigallocatechin concentrations, while the concentration of catechin in the samples from Series 1 and 2 was similar, and slightly higher in the extracts from Series 3 (Figure 3). The main conclusion that could be withdrawn from the experimental data is that $98 \% \mathrm{EtOH}$ is not an appropriate extracting agent of flavonoids from woundwort. Besides, due to the observed twice lower content of epigallocatechin in the extracts from Series 4 as compared 
to that for Series 1 and 2, on the one hand, and the lower stability of the aqueous extracts as compared to these in ethanol or methanol, on the other, water could not be accepted as an appropriate solvent either.

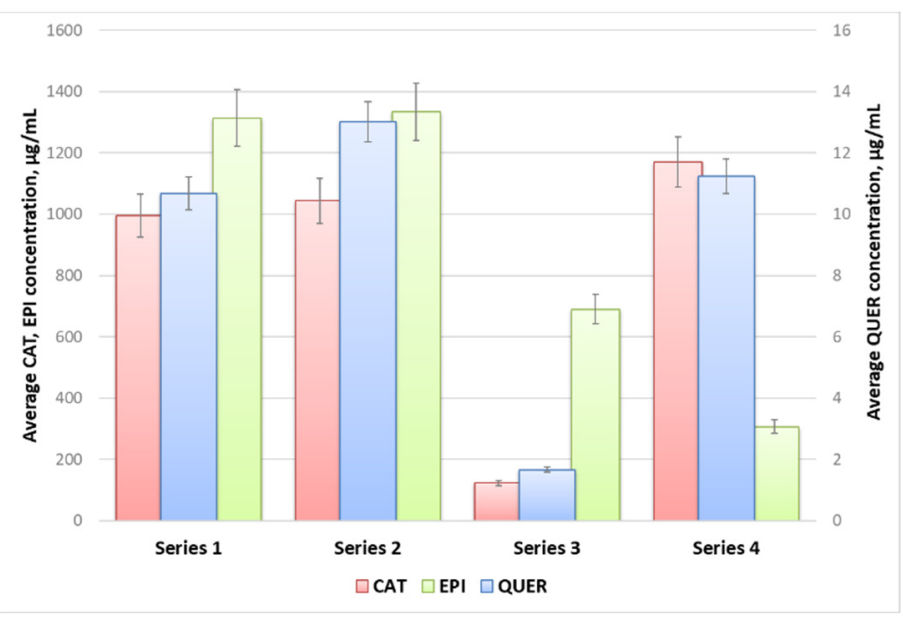

Figure 3. Average catechin (CAT), epigallocatechin (EPI) and quercetin (QUER) concentrations in the woundwort extracts from Series $1-4$.

\subsection{FT-IR Analyses}

FT-IR spectroscopy is currently one of the most significant analytical techniques available for quantitative and qualitative analyses of plant extracts due to its sensitivity, non-destructive nature, small sample quantities, as well as the possibility for simultaneous determination of various constituents in the same sample from a single measurement [36].

Three samples from Series 2: S3, S4 and S5, obtained at extraction times $20 \mathrm{~min}, 30 \mathrm{~min}$ and $60 \mathrm{~min}$, respectively, were chosen as representatives of the ethanol woundwort extracts. The FT-IR spectral data are presented in Figure 4 and the wavelengths of the characteristic bands together with the corresponding designations-in Table 2.

The bands between $1600 \mathrm{~cm}^{-1}$ and $1500 \mathrm{~cm}^{-1}$ correspond to the $\mathrm{C}=\mathrm{C}$ stretching of the aromatic ring. Peaks within this region are characteristic of all extracts which indicates the presence of the aromatic compounds catechin, epigallocatechin and quercetin. The region at around $1500-1400 \mathrm{~cm}^{-1}$ represents $\mathrm{C}-\mathrm{C}$ stretching of aromatic rings and $\mathrm{C}-\mathrm{H}$ bending vibrations. The highest peaks are recorded for S5, although the intensities of the bands for the three samples are not significant. The bands between $1300 \mathrm{~cm}^{-1}$ and $100 \mathrm{~cm}^{-1}$ are typically assigned to $\mathrm{C}-\mathrm{O}$ stretching vibrations, $\mathrm{C}-\mathrm{O}-\mathrm{H}$ bending, plane bending vibrations of phenyl group and $\mathrm{C}=\mathrm{C}-\mathrm{O}$ aromatic ring stretching. The presence of multiple peaks in the spectra of the extracts, although not as well pronounced as in these of the pure flavonoids, is indicative of the presence of pyrogallic rings. The low wavenumber region below $1000 \mathrm{~cm}^{-1}$ represents many molecular vibrations, $\mathrm{C}-\mathrm{O}-\mathrm{C}$ symmetric stretching, $\mathrm{C}-\mathrm{H}$ aromatic bending, $\mathrm{H}$ out-of-plane deformation of an aromatic ring, aromatic ring vibrations, $\mathrm{C}-\mathrm{H}$ alkenes, stretching of the catechol moiety. Significant deviations were not registered in the bands' intensities between the pure substances and the extracts.

The comparative analyses between the FT-IR spectra of the extracts and the three pure flavonoids (Table 2) undoubtedly prove that the herbal medicinal plant contains catechin, epigallocatechin and quercetin. Besides, the gradual increase of the peak intensities of the extract samples was directly proportional to the increase of the polyphenols concentrations. 
Table 2. FT-IR absorption bands assignments of ethanol woundwort extracts, powdered pure powdered catechin, epigallocatechin and quercetin [37-40].

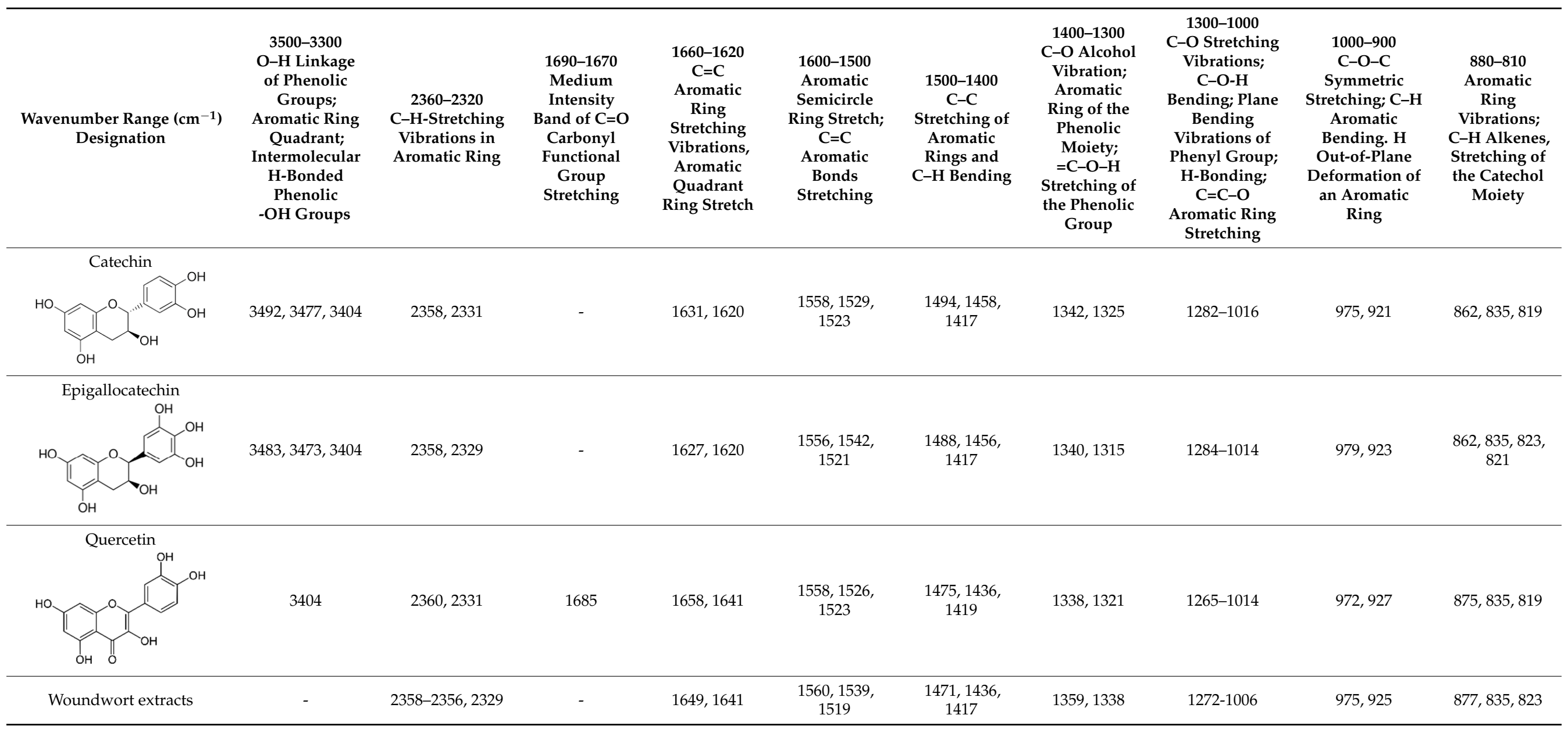




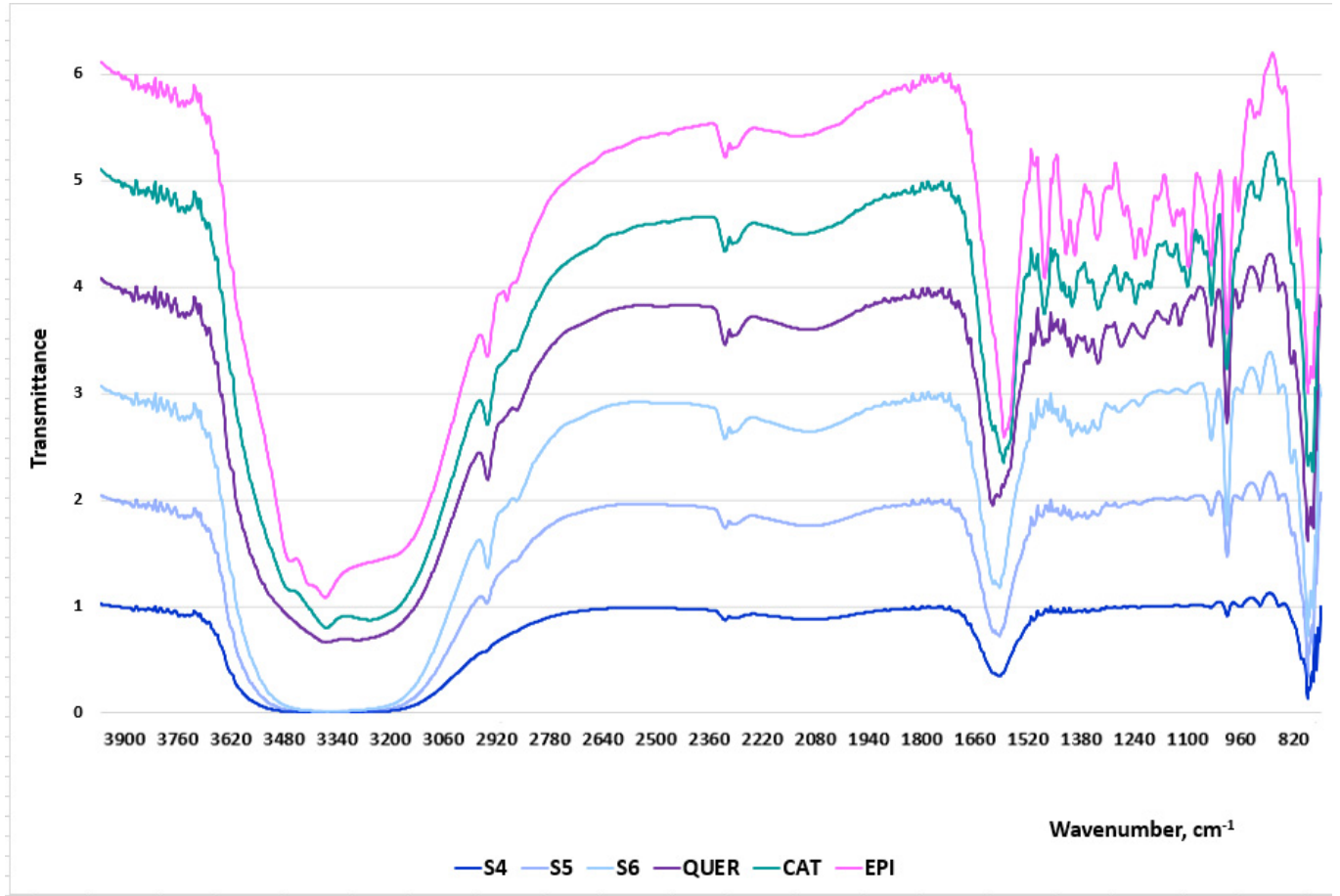

Figure 4. FT-IR spectra of the woundwort extracts: S4, S5 and S6, pure powdered catechin, epigallocatechin and quercetin.

\subsection{Antibacterial Activity of Woundwort Extracts}

The antibacterial activity of the woundwort samples from Series 1-3 was evaluated against four bacterial strains using the agar well diffusion method. We selected the following four strains as classical representatives of the two groups of bacteria differing in the structure of their cell walls-Gram-positive including Staphylococcus aureus ATCC 25923 and Bacillus cereus (clinical isolate) and Gram-negative including Escherichia coli ATCC 25922 and Pseudomonas aeruginosa ATCC 27853, the latter having intrinsic multiple antimicrobial resistance. The reference strains are also used as test quality strains in performing antimicrobial susceptibility tests (CLSI) [41]. In addition, S. aureus, E. coli and P. aeruginosa are causative agents of mild to severe infections in both human and veterinary medicine, including on the urinary tract where the woundwort extracts are deemed as potentially helpful. B. cereus is related to food poisoning, systemic and focal infections in immunocompromised patients. All this prompted us to test the antimicrobial properties of woundwort extracts from Bulgaria against these four strains in the present study.

Gentamicin was selected as a positive control for the antimicrobial investigations as it displays satisfactory antimicrobial efficiency against the four studied strains. The growth inhibition zones of gentamicin relative to the reference strains used in the present study are fully consistent with the CLSI [41] interpretive criteria. Regarding B. cereus, the activity of gentamicin against this clinical isolate was confirmed in other studies [42].

The values of the corresponding inhibition zones (IZ, $\mathrm{mm}$ ) are presented in Table 3. Series 4 extracts were not subjected to antimicrobial screening due to the significantly lower concentrations of the studied flavonoids, as well as due to the deviations in the modes of the experimental kinetics curves. The data outlined the potential of the tested extracts in suppressing microbial growth of food poisoning bacteria with variable activity. It was established that the samples from Series 1 were the most effective extracts retarding the microbial growth of $P$. aeruginosa and S. aureus. The samples from the other two series exhibited satisfactory efficiency against three of the strains-P. aeruginosa, S. aureus and E. coli. The general conclusion that could be drawn, however, is that the ethanol woundwort extracts were ineffective against $B$. cereus as neither of the samples suppressed the microbial growth of the strain. 
Table 3. Antimicrobial screening test results (IZ $\pm \mathrm{SD}$ ) of ethanol woundwort extracts against four bacterial strains-S. aureus, P. aeruginosa, E. coli and B. cereus.

\begin{tabular}{|c|c|c|c|c|c|c|c|c|c|c|c|c|}
\hline \multirow{2}{*}{ Sample } & \multicolumn{4}{|c|}{ Series 1 IZ } & \multicolumn{4}{|c|}{ Series 2 IZ } & \multicolumn{4}{|c|}{ Series $3 \mathrm{IZ}$} \\
\hline & S. aureus & P. aeruginosa & E. coli & B. cereus & S. aureus & P. aeruginosa & E. coli & B. cereus & St. aureus & P. aeruginosa & E. coli & B. cereus \\
\hline $\mathrm{S}^{\prime} / \mathrm{S} 1 / \mathrm{S} 1^{\prime \prime}$ & $12.8 \pm 0.3^{* *}$ & $25.2 \pm 1.0 * * *$ & - & - & - & - & $8.8 \pm 0.8^{*}$ & - & $9.0 \pm 0.5^{*}$ & - & $8.5 \pm 0.5^{*}$ & - \\
\hline $\mathrm{S}^{\prime} / \mathrm{S} 2 / \mathrm{S} 2^{\prime \prime}$ & $17.2 \pm 0.8^{* * *}$ & $24.2 \pm 0.8^{* * *}$ & - & - & $8.7 \pm 0.6^{*}$ & $8.7 \pm 0.6^{*}$ & $8.3 \pm 0.6^{*}$ & - & $9.5 \pm 0.9^{*}$ & $8.8 \pm 0.3^{*}$ & $8.7 \pm 0.6^{*}$ & - \\
\hline $\mathrm{S}^{\prime} / \mathrm{S} 3 / \mathrm{S}^{\prime \prime}$ & $21.0 \pm 1.0^{* * *}$ & $21.2 \pm 0.8^{* * *}$ & - & - & $9.2 \pm 0.3^{*}$ & $8.8 \pm 0.8^{*}$ & $8.7 \pm 0.6^{*}$ & - & $9.7 \pm 0.3^{*}$ & $8.5 \pm 0.9^{*}$ & $9.5 \pm 0.5^{*}$ & - \\
\hline $\mathrm{S}^{\prime} / \mathrm{S} 4 / \mathrm{S} 4^{\prime \prime}$ & $11.7 \pm 1.5^{* *}$ & $14.2 \pm 1.0^{* *}$ & - & - & $9.2 \pm 0.3^{*}$ & $9.7 \pm 0.6^{*}$ & $9.2 \pm 0.8^{*}$ & - & $9.7 \pm 0.6^{*}$ & $9.3 \pm 0.6^{*}$ & $8.8 \pm 0.3^{*}$ & - \\
\hline $\mathrm{S}^{\prime} / \mathrm{S} 5 / \mathrm{S}^{\prime \prime}$ & $16.8 \pm 0.8^{* * *}$ & $11.3 \pm 1.5^{* *}$ & - & - & $9.7 \pm 0.6^{*}$ & $9.5 \pm 0.5^{*}$ & $8.5 \pm 0.5^{*}$ & - & $9.0 \pm 1.0^{*}$ & - & - & - \\
\hline $\mathrm{S} 6^{\prime} / \mathrm{S} 6 / \mathrm{S} 6^{\prime \prime}$ & $14.8 \pm 0.3^{* *}$ & - & - & - & $10.7 \pm 1.2 *$ & $9.2 \pm 0.8^{*}$ & $8.5 \pm 0.9$ * & - & $9.2 \pm 1.0 *$ & - & - & - \\
\hline $\begin{array}{c}\text { Positive } \\
\text { control } \\
\text { (gentamicin) }\end{array}$ & $17.2 \pm 0.8$ & $17.0 \pm 0.5$ & $16.2 \pm 1.0$ & $18.2 \pm 0.8$ & $18.7 \pm 0.6$ & $17.3 \pm 0.6$ & $16.8 \pm 0.3$ & $18.5 \pm 0.5$ & $18.2 \pm 0.8$ & $16.7 \pm 0.6$ & $16.5 \pm 0.5$ & $18.7 \pm 0.3$ \\
\hline $\begin{array}{c}\text { Negative } \\
\text { control (70\% } \\
\text { EtOH; } 98 \% \\
\text { EtOH) }\end{array}$ & $8.2 \pm 0.3$ & $7.5 \pm 0.5$ & $7.8 \pm 0.3$ & $10.8 \pm 0.8$ & $8.2 \pm 0.3$ & $7.5 \pm 0.5$ & $7.8 \pm 0.3$ & $10.8 \pm 0.8$ & $7.2 \pm 0.3$ & $7.5 \pm 0.5$ & $8.2 \pm 0.5$ & $9.8 \pm 0.8$ \\
\hline
\end{tabular}

IZ-inhibition zone, $\mathrm{mm} ;{ }^{*}$ low antibacterial activity $(\mathrm{IZ}=8-10 \mathrm{~mm}){ }^{* *}$ medium antibacterial activity $(\mathrm{IZ}=11-14 \mathrm{~mm}){ }^{* * *}$ high antibacterial activity $(\mathrm{IZ} \geq 15 \mathrm{~mm})$. 
Regarding the effect of the flavonoids (catechin, epigallocatechin and quercetin) concentrations on the antibacterial activity of woundwort, significant correlation and direct dependence was registered only between the antimicrobial potential of the samples from Series 2 against the inhibition zones of $S$. aureus with the maximum coefficient of determination $R^{2}=0.893, p<0.05$. Thus these results were graphically represented in Figure 5 . The highest $\mathrm{R}^{2}$ value for Series 1 and 3 were $\mathrm{R}^{2}=0.662(p<0.05)$ and $\mathrm{R}^{2}=0.135(p<0.05)$, respectively.

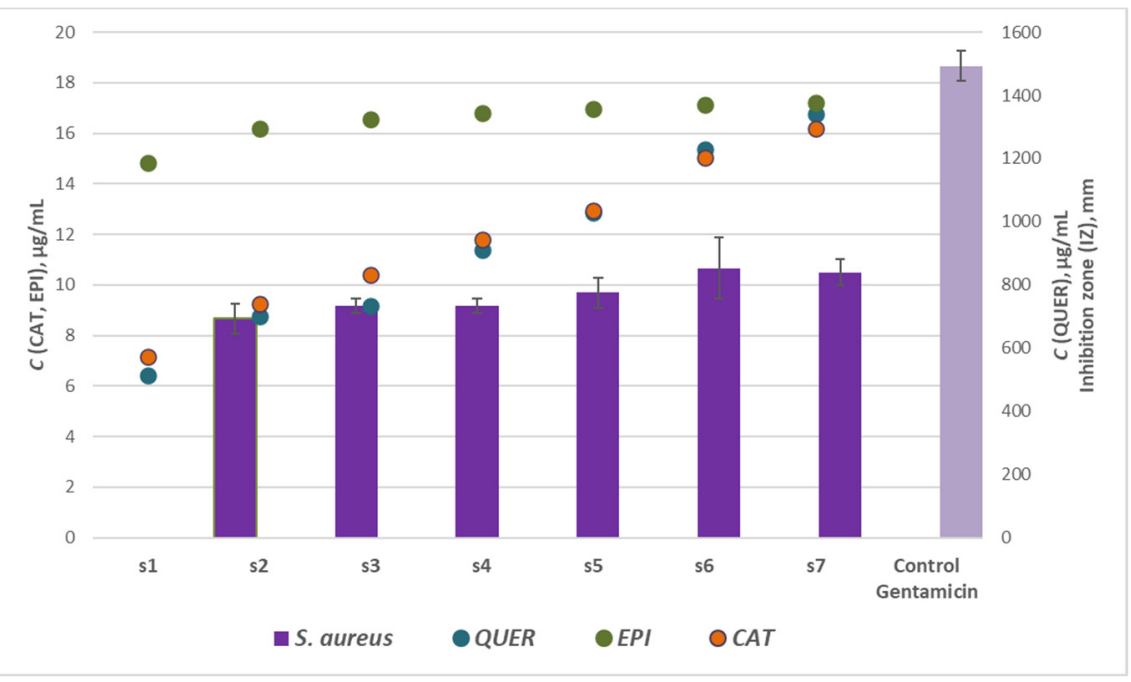

Figure 5. Effect of flavonoids: catechin (CAT), epigallocatechin (EPI) and quercetin (QUER), concentrations on the antibacterial activity of Series 2 woundwort extracts against $S$. aureus.

The recent investigations suggest that B. cereus was the most resistant strain to woundwort followed by E. coli, while S. aureus and P. aeruginosa were the most susceptible microbial strains to the medicinal plant extract. The latter conclusion is scientifically significant as scientific data have not reported any results on the antibacterial potential of the plant extract against $B$. cereus strain.

\subsection{Antioxidant Activity and Radical-Scavenging Potential of Woundwort Extracts}

The antioxidant activity and antiradical potential of four woundwort extracts from Series 1 (samples S8' and S9' with quercetin concentration 13.7 and $17.9 \mu \mathrm{g} / \mathrm{mL}$, respectively) and Series 2 (samples S8 and S9 with quercetin concentration 17.5 and $18.9 \mu \mathrm{g} / \mathrm{mL}$, respectively) was studied. Quercetin solution in ethanol $(50 \mu \mathrm{g} / \mathrm{mL})$ was used as a positive control.

Flavonoids take beneficial place in the UV oxidative stress protection and regulation due to their antioxidant potential. According to recent studies some plants characterize with independent photoprotective systems and their exposure to UV-B radiation stimulated higher levels of flavonoids biosynthesis and ROS removal [43]. The latter observations provoked the additional subjection to UV-B irradiation of samples S8 and S9 to evaluate its effect on the antioxidant properties of the medicinal plant extracts.

\subsection{DPPH Scavenging Activity}

According to the data in Figure 6A the DPPH radical scavenging activities of the tested woundwort samples were higher than that of the positive control. Sample S9 exhibited the highest antioxidant activity, which was additionally increased by $7.2 \%$ after UV-B irradiation. The irradiation, however, did not affect the DPPH scavenging activity of S8. These results were confirmed by the antioxidant activity kinetics experiments (Figure 6B). Although the antioxidant activity of samples $S 8^{\prime}$ and $S 9^{\prime}$ remains relatively stable up to the $20 \mathrm{~min}$, the kinetics curves clearly outline their significantly lower initial antioxidant activity as compared to S8 and S9. From another aspect, UV-B irradiator slightly increased 
the antioxidant potential of sample S8 but it did not alter the mode of the kinetics curve. The plot of sample S9 displayed quite different mode of antioxidant kinetics and the initial part is indicative of lower stability of the extract up to the $15 \mathrm{~min}$. However, UV-B irradiation obviously increased this antioxidant stability and activity of the extract and additionally decreased the rate of DPPH radical scavenging activity loss as the plot slope between 25 and $45 \mathrm{~min}$ was smoothened.

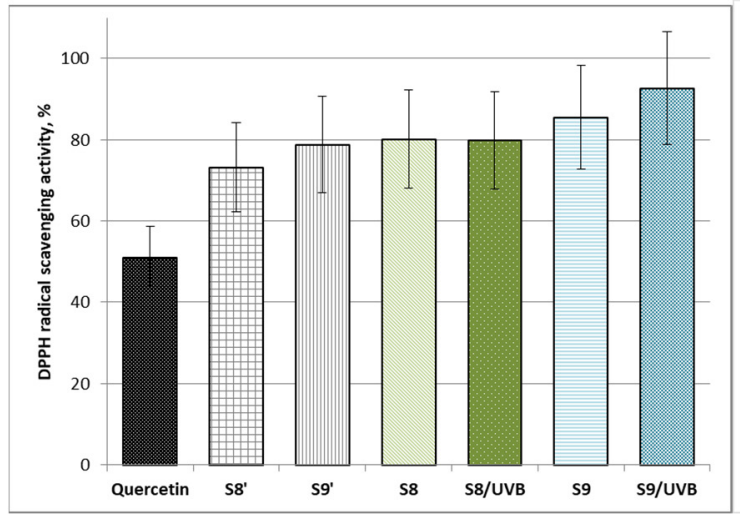

(A)

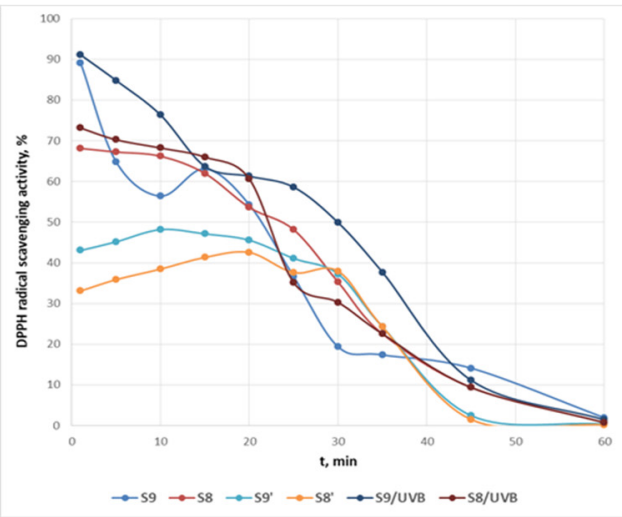

(B)

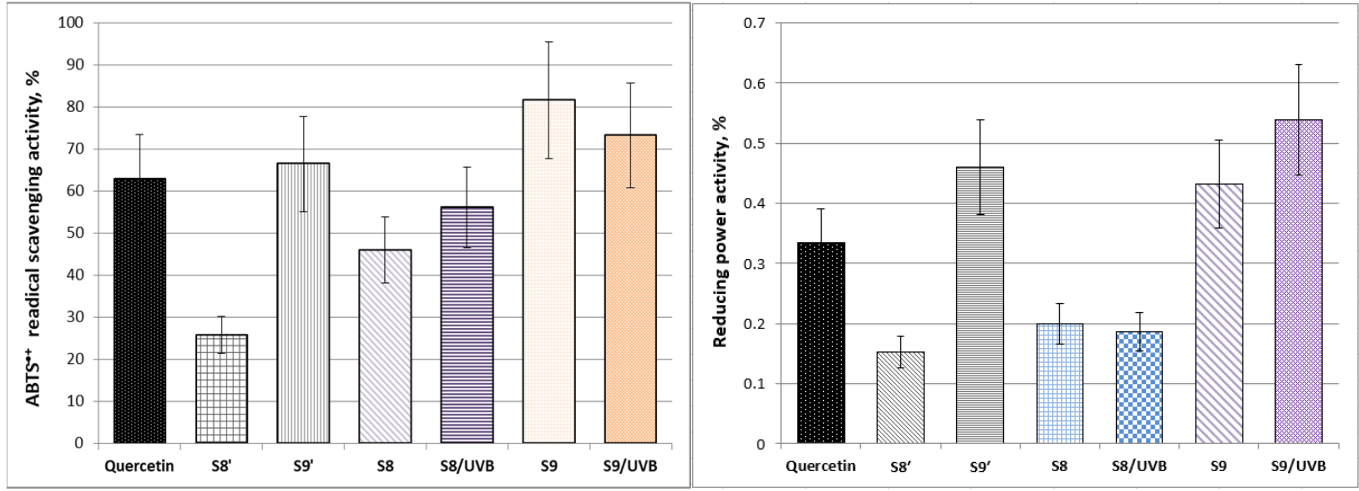

(C)

(D)

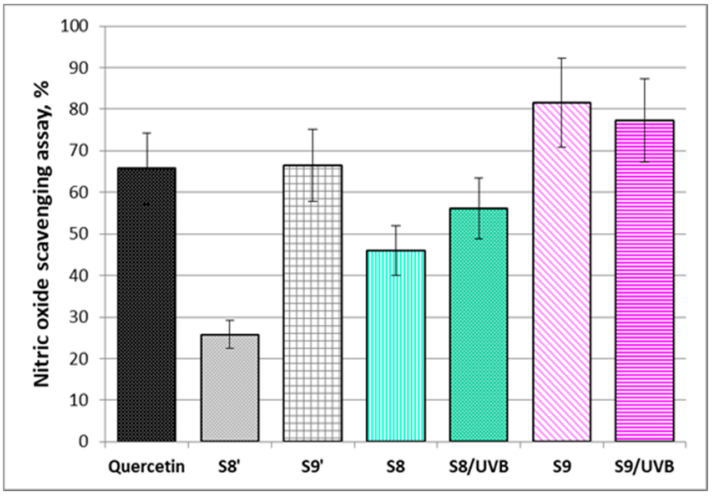

(E)

Figure 6. Antioxidant activity and radical-scavenging potential of woundwort extracts: (A). DPPH radical-scavenging activity, \% ( \pm SD); (B). Kinetics of DPPH radical-scavenging activity; (C). ABTS ${ }^{\bullet+}$ radical scavenging activity, \% ( \pm SD); (D). Reducing power activity, \% ( \pm SD); (E). Nitric oxide scavenging assay, $\%( \pm \mathrm{SD})$.

\subsection{ABTS $^{\bullet+}$ Radical Scavenging Activity}

The proton-radical analysis (ABTS ${ }^{\bullet+}$ method) was applied to define the total antioxidant activity of the woundwort extracts. The experimental data presented in Figure 6C 
clearly outline that samples S9 and S9' ${ }^{\prime}$ were more effective in quenching proton radicals in the system as compared to the control and to samples S8 and S8'. The probable reason is the higher contents of flavonoids in the samples due to the longer extraction time. Besides, according to the present investigations after UV-B-irradiation sample S9 has accumulated active components and maintains $\mathrm{ABTS}^{\bullet+}$ reduction level higher than that of pure quercetin. The possible explanation is probable stimulation of the production of secondary metabolites and antioxidant potential by UV-B irradiation, which in turn provokes the ability of adaptation and protection of the extract from the irradiation impact [44].

\subsection{Reducing Power Activity}

Ferric reducing antioxidant power (FRAP) assay is associated with the antioxidant potential of plants extracts through the reduction of ferric iron $\left(\mathrm{Fe}^{3+}\right)$ to ferrous iron $\left(\mathrm{Fe}^{2+}\right)$ due to the donation of hydrogen atoms by the antioxidants that are present in the studied samples [45]. The data of the ferric reducing activity of the four tested woundwort extracts are presented in Figure 6D. The FRAP activity of samples S9' and S9 exceeded that of the positive control and samples S8 ${ }^{\prime}$ and S8. UV-B irradiation did not influence the reducing power activity of S8, while it increased the activity of S9 by approximately $25 \%$.

\subsection{Nitric Oxide Scavenging Assay}

Nitric oxide scavenging assay evaluates the potential of natural biologically active compounds to counteract the effect of $\mathrm{NO}^{\bullet}$ radicals formation, e.g., through arresting the chain of reactions initiated by excessive $\mathrm{NO}^{\bullet}$ generation and in turn assist the prevention of arising detrimental health effects such as oxidative cell damages and compromised cell NOfunctionality [46]. In this respect, the present study provided evidence of the satisfactory NO scavenging ability of sample S9 before and after UV-B irradiation, which prevailed that of the reference standard (Figure 6E). The experimental data indicated commensurable NO scavenging activity of sample S9' and quercetin. Considering the lower concentration of the flavonoid in the sample $(17.9 \mu \mathrm{g} / \mathrm{mL})$ as compared to the pure substance $(50 \mu \mathrm{g} / \mathrm{mL})$, it could be concluded that the scavenging potential of the extract is higher than the standard. UV-B irradiation did not affect significantly the NO radical scavenging potential of samples S8/UV-B and S9/UV-B. The polyphenols quercetin, catechin and epigallocatechin contained in these extracts serve as donors of hydrophilic scavengers that are able to regulate $\mathrm{NO}^{\bullet}$ production even under UV-B irradiation. According to scientific reports endogenous NO production is capable of modulating the redox state of the mitochondrial electron transport chain, primary metabolism and oxidative stress signaling $[47,48]$.

The experimental results emphasized that the antioxidant capacity and radical scavenging activity of ethanol woundwort extracts depend directly on the extraction time, i.e., on the concentration of the flavonoids quercetin, catechin and epigallocatechin, as well as on the extraction methodology. Besides, the tested samples S9' and S9 exhibited satisfactory antioxidant ability which even exceeded that of pure quercetin which concentration $(50 \mu \mathrm{g} / \mathrm{mL})$ was significantly higher than that determined in two of the analyzed extracts $\left(S^{\prime}-17.95\right.$ and $S 9-18.90 \mu \mathrm{g} / \mathrm{mL}$ ). A reasonable explanation is the additional capacity of the catechins contained in the extract which enhance the activity and stability of the medicinal plant to oxidative stress even under UV-B irradiation by donating excessive hydroxyl radicals. The latter determines the role of these bioactive components as potential effective photoprotectors and ROS/NO scavengers formed through UV-B exposure.

\section{Conclusions}

The present study assessed the kinetics of catechin, epigallocatechin and quercetin from Bulgarian woundwort water and ethanol extracts, the antibacterial potential of $70 \%$ and 96\% ethanol extracts against four bacterial strains (Staphylococcus aureus ATCC25923, Escherichia coli ATCC 25922, Pseudomonas aeruginosa ATCC 27853 and Bacillus cereus), their antioxidant capacity and radical scavenging potential. According to the RP-HPLC-PDA data and the FT-IR analyses the contents of the natural flavonoids in the ethanol extracts 
followed the order: epigallocatechin $>$ catechin $>$ quercetin. The kinetics of the extraction process revealed that the $70 \%$ and $96 \%$ ethanol extracts were the richest in flavonoids and were therefore subjected to antimicrobial and antioxidant assays. The plant extracts from Series 1 (solvent $70 \% \mathrm{EtOH}$, extraction temperature $\mathrm{T}=20^{\circ} \mathrm{C}$ ), which proved to be potentially effective against $S$. aureus and P. aeruginosa, can find application as alternative natural preservatives to control food poisoning diseases and preserve food stuff avoiding the use of health hazardous chemical antimicrobial agents. It was established that the antioxidant potential and radical scavenging activity of ethanol woundwort extracts depended directly on the extraction time, i.e., on the concentration of quercetin, catechin and epigallocatechin, as well as on the extraction methodology. Two of the tested samples (extracted with $70 \%$ EtOH at $20^{\circ} \mathrm{C}$ and $30^{\circ} \mathrm{C}$ ) exhibited satisfactory antioxidant ability which even exceeded that of pure quercetin with higher concentration. Consequently, the ethanol extracts of the Bulgarian medicinal plant have been proven as efficient radical scavengers which could be used to minimize oxidative stress caused by reactive oxygen species.

Supplementary Materials: The following are available online at https: / www.mdpi.com/article / 10.3390/separations9020027/s1, Figure S1: Calibration curves of the standard compounds A. (+)catechin hydrate; B. (-)-epigallocatechin and C. quercetin hydrate; Table S1: Concentrations of the flavonoids quercetin, epigallocatechin and catechin in the samples of the four goldenrod extracts series.

Author Contributions: Conceptualization, Z.Y., E.S. and D.I.; methodology, Z.Y., E.S., N.R. and Y.K.; investigation, Z.Y., E.S., C.C., N.R., G.B., D.I. and G.N.; data curation, Z.Y., C.C., Y.K. and N.R.; writing-original draft preparation, Z.Y., E.S., D.I., N.R. and Y.K.; writing-review and editing, Z.Y., E.S., N.R. and Y.K.; supervision, Z.Y. and E.S. All authors have read and agreed to the published version of the manuscript.

Funding: This work was supported by the Bulgarian Ministry of Education and Science under the National Research Programme "Healthy Foods for a Strong Bio-Economy and Quality of Life" approved by DCM \# 577/17.08.2018" and Scientific project 06/2021 FVM, Trakia University, Stara Zagora, Bulgaria.

Institutional Review Board Statement: Not applicable.

Informed Consent Statement: Not applicable.

Data Availability Statement: Data is contained within the article.

Conflicts of Interest: The authors declare no conflict of interest.

\section{References}

1. Nasseri, M.A.; Behravesh, S.; Allahresani, A.; Kazemnejadi, M. Phytochemical and antioxidant studies of Cleome heratensis (Capparaceae) plant extracts. Bioresour. Bioprocess. 2019, 6, 5. [CrossRef]

2. Szerlauth, A.; Muráth, S.; Viskic, S.; Szilagyi, I. Radical scavenging activity of plant extracts from improved processing. Heliyon 2019, 5, e02763. [CrossRef]

3. Saeed, N.; Khan, M.R.; Shabbir, M. Antioxidant activity, total phenolic and total flavonoid contents of whole plant extracts Torilis leptophylla L. BMC Complement. Altern. Med. 2012, 12, 221. [CrossRef]

4. $\quad$ Chaves, J.O.; de Souza, M.C.; da Silva, L.C.; Lachos-Perez, D.; Torres-Mayanga, P.C.; Machado, A.P.d.F.; Forster-Carneiro, T.; Vázquez-Espinosa, M.; González-de-Peredo, A.V.; Barbero, G.F.; et al. Extraction of flavonoids from natural sources using modern techniques. Front. Chem. 2020, 8, 507887. [CrossRef]

5. Zhou, J.; Yang, Q.; Zhu, X.; Lin, T.; Hao, D.; Xu, J. Antioxidant activities of Clerodendrum cyrtophyllum Turcz leaf extracts and their major components. PLoS ONE 2020, 15, e0234435. [CrossRef] [PubMed]

6. Yu, M.; Gouvinhas, I.; Rocha, J.; Barroset, A.I.R.N.A. Phytochemical and antioxidant analysis of medicinal and food plants towards bioactive food and pharmaceutical resources. Sci. Rep. 2021, 11, 10041. [CrossRef]

7. Al-Rifai, A.; Aqel, A.; Al-Warhi, T.; Wabaidur, S.M.; Al-Othman, Z.A.; Badjah-Hadj-Ahmed, A.Y. Antibacterial, antioxidant activity of ethanolic plant extracts of some Convolvulus species and their DART-TOF-MS profiling. Evid.-Based Complementary Altern. Med. 2017, 2017, 5694305. [CrossRef]

8. Onivogui, G.; Letsididi, R.; Diaby, M.; Wang, L.; Song, Y. Influence of extraction solvents on antioxidant and antimicrobial activities of the pulp and seed of Anisophyllea laurina R. Br. ex Sabine fruits. Asian Pac. J. Trop. Biomed. 2016, 6, 20-25. [CrossRef] 
9. Gonelimali, F.D.; Lin, J.; Miao, W.; Xuan, J.; Charles, F.; Chen, M.; Hatab, S.R. Antimicrobial properties and mechanism of action of some plant extracts against food pathogens and spoilage microorganisms. Front. Microbiol. 2018, 9, 1639. [CrossRef] [PubMed]

10. Dissanayake, D.M.I.H.; Perera, D.D.B.D.; Keerthirathna, L.R.; Heendeniya, S.; Anderson, R.J.; Williams, D.E.; Peiris, L.D.C. Antimicrobial activity of Plumbago indica and ligand screening of plumbagin against methicillin-resistant Staphylococcus aureus. J. Biomol. Struct. Dyn. 2020. [CrossRef]

11. Manandhar, S.; Luitel, S.; Dahal, R.K. In vitro antimicrobial activity of some medicinal plants against human pathogenic bacteria. J. Trop. Med. 2019, 2019, 1895340. [CrossRef]

12. Owusu, E.; Ahorlu, M.M.; Afutu, E.; Akumwena, A.; Asare, G.A. Antimicrobial activity of selected medicinal plants from a Sub-Saharan African country against bacterial pathogens from post-operative wound infections. Med. Sci. 2021, 9, 23. [CrossRef]

13. Tungmunnithum, D.; Thongboonyou, A.; Pholboon, A.; Yangsabai, A. Flavonoids and other phenolic compounds from medicinal plants for pharmaceutical and medical aspects: An Overview. Medicines 2018, 5, 93. [CrossRef]

14. Al-Trad, B.; Al-Qudah, M.A.; Al-Zoubi, M.; Al-Masri, A.; Muhaidat, R.; Qar, J.; Alomari, G.; Alrabadi, N.I. In-vitro and in-vivo antioxidant activity of the butanolic extract from the stem of Ephedra alte. Biomed. Pharmacol. J. 2018, 11, 1239-1245. [CrossRef]

15. Moraisi, G.; Ireri, A.; Ngugi, M.P. In vitro antioxidant activities of the aqueous and methanolic stem bark extracts of Piliostigma thonningii (Schum.). J. Evid.-Based Integr. Med. 2020, 25, 1-9. [CrossRef]

16. Zagórska-Dziok, M.; Ziemlewska, A.; Nizioł-Łukaszewska, Z.; Bujak, T. Antioxidant activity and cytotoxicity of Medicago sativa L. seeds and herb extract on skin cells. BioRes. Open Access 2020, 9, 229-242. [CrossRef]

17. Fursenco, C.; Calalb, T.; Uncu, L.; Dinu, M.; Ancuceanu, R. Solidago virgaurea L.: A Review of its ethnomedicinal uses, phytochemistry, and pharmacological activities. Biomolecules 2020, 10, 1619. [CrossRef]

18. Jasicka-Misiak, I.; Makowicz, E.; Stanek, N. Chromatographic fingerprint, antioxidant activity, and colour characteristic of polish woundwort (Solidago virgaurea L.) honey and flower. Eur. Food Res. Technol. 2018, 244, 1169-1184. [CrossRef]

19. Yaneva, Z.; Ivanova, D.; Beev, G.; Besheva, K. Quantification of catechin in Acacia catechu extract by non-derivative, first derivative UV/Vis spectrophotometry and FT-IR spectroscopy. Bulg. Chem. Commun. 2020, 52, 41-47.

20. Yaneva, Z. Development of a new precise and sensitive analytical method for quercetin quantification. Proc. Univ. Ruse 2018, 57, 153-157.

21. Kaneria, M.; Baravalia, Y.; Vaghasiya, Y.; Chanda, S. Determination of antibacterial and antioxidant potential of some medicinal plants from Saurashtra region, India. Indian J. Pharm. Sci. 2009, 71, 406-412. [CrossRef]

22. Cuendet, M.; Hostettmann, K.; Potterat, O.; Dyatmiko, W. Iridoid glucosides with free radical scavenging properties from Fagraea blumei. Helv. Chim. Acta 1997, 80, 1144-1152. [CrossRef]

23. Karamalakova, Y.; Sharma, J.; Sharma, R.K.; Gadjeva, V.; Kumar, R.; Zheleva, A. Comparative investigation on radical scavenging activity and protective properties of natural isolated and synthetic antioxidants. Biotechn. Biotechnol. Equipm. 2012, 26 (Suppl. 1), 175-179. [CrossRef]

24. Re, R.; Pellegrini, N.; Proteggente, A.; Pannala, A.; Yang, M.; Rice-Evans, C. Antioxidant activity applying an improved ABTS radical cation decolorization assay. Free Rad. Biol. Med. 1999, 26, 1231-1237. [CrossRef]

25. Adhikary, M.; Karamalakova, Y.; Ivanov, V.; Gadjeva, V.; Kumar, R.; Sharma, R.; Zheleva, A.; Arora, R. A comparative evalution of an antioxidant of natural origin derived from Silybum marianum characterized by in vitro assay and electron paramagnetic resonance spectroscopy. Trakia J. Sci. 2012, 10 (Suppl. 1), 17-24. [CrossRef]

26. Oyaizu, M. Studies on products of Browning reactions: Antioxidative activities of product of Browning reaction prepared from glucosamine. Jpn. J. Nutr. 1986, 44, 307-315. [CrossRef]

27. Karamalakova, Y.; Sharma, J.; Nikolova, G.; Stanev, S.; Arora, R.; Gadjeva, V.; Zheleva, A. Studies on antioxidant properties before and after UV- And $\Gamma$-Irradiation of Bulgarian lavender essential oil isolated from Lavandula Angostifolia mill. Biotechnol. Biotechnol. Equipm. 2013, 27, 3861-3865. [CrossRef]

28. Shirwaikar, A.; Prabhu, K.S.; Punitha, I.S. In vitro antioxidant studies of Sphaeranthus indicus (Linn). Indian J. Exp. Biol. 2006, 44, 993-996.

29. Karamalakowa, Y.; Adhikary, M.; Kovacheva, N.; Ivanov, V.; Nikolova, G.; Gadjeva, V. Rose oil isolated from oil-bearing Rosa damascena Mill. As a protector against ionizing radiation-induced oxidative disorders. Bulg. Chem. Commun. 2018, 50, 14-19.

30. Tzanova, M.; Atanasov, V.; Yaneva, Z.; Ivanova, D.; Dinev, T. Selectivity of current extraction techniques for flavonoids from plant materials. Processes 2020, 8, 1222. [CrossRef]

31. Simeonov, E.; Yaneva, Z.; Chilev, C. Kinetics of green solid-liquid extraction of useful compounds from plant materials-Kinetics coefficients and modelling. Green Processing Synth. 2018, 7, 68-73. [CrossRef]

32. Simeonov, E.; Yaneva, Z.; Chilev, C. Extraction of protodioscin from Tribulus terrestris-Optimisation of kinetics and modelling Rev. Chim. 2020, 71, 56-66. [CrossRef]

33. Koch, W.; Kukuła-Koch, W.; Czop, M.; Helon, P.; Gumbarewicz, E. The role of extracting solvents in the recovery of polyphenols from green tea and its antiradical activity supported by principal component analysis. Molecules 2020, 25, 2173. [CrossRef]

34. Vuong, Q.V.; Golding, J.B.; Nguyen, M.; Roach, P.D. Extraction and isolation of catechins from tea. J. Sep. Sci. 2010, $33,3415$. [CrossRef] [PubMed]

35. Tsai, Y.J.; Chen, B.H. Preparation of catechin extracts and nanoemulsions from green tea leaf waste and their inhibition effect on prostate cancer cell PC-3. Int. J. Nanomed. 2016, 11, 1907. [CrossRef] 
36. Brangule, A.; Šukele, R.; Bandere, D. Herbal medicine characterization perspectives using advanced FTIR sample techniquesDiffuse Reflectance (DRIFT) and Photoacoustic Spectroscopy (PAS). Front. Plant Sci. 2020, 11, 356. [CrossRef]

37. Srinivas, K.; King, J.W.; Howard, L.R.; Monrad, J.K. Solubility and solution thermodynamic properties of quercetin and quercetin dihydrate in subcritical water. J. Food Eng. 2010, 100, 208-218. [CrossRef]

38. Wang, Q.; Wei, H.; Deng, C.; Xie, C.; Huang, M.; Zheng, F. Improving stability and accessibility of quercetin in olive oil-in-soy protein isolate/pectin stabilized O/W emulsion. Foods 2020, 9, 123. [CrossRef] [PubMed]

39. Porto, I.C.C.M.; Nascimento, T.G.; Oliveira, J.M.S.; Freitas, P.H.; Haimeur, A.; França, R. Use of polyphenols as a strategy to prevent bond degradation in the dentin-resin interface. Eur. J. Oral Sci. 2018, 126, 146-158. [CrossRef]

40. Ke, F.; Zhang, M.; Qin, N.; Zhao, G.; Chu, J.; Wan, X. Synergistic antioxidant activity and anticancer effect of green tea catechin stabilized on nanoscale cyclodextrin-based metal-organic frameworks. J. Mater. Sci. 2019, 54, 10420-10429. [CrossRef]

41. Watts, J.L.; Shryock, T.R.; Apley, M.; Bade, D.J.; Brown, S.D.; Gray, J.T.; Heine, H.; Hunter, R.P.; Mevius, D.J.; Papich, M.G.; et al. Performance Standards for Antimicrobial Disk and Dilution Susceptibility Tests for Bacteria Isolated from Animals, 3rd ed.; Clinical and Laboratory Standards Institute: Wayne, PA, USA, 2008; Volume 28, No 8; p. 99.

42. Dinev, T.; Tzanova, M.; Rusenova, N.; Grozeva, N.; Gerdzhikova, M.; Beev, G. Antimicrobial and antioxidant potential of methanolic extracts from different parts of Stevia rebaudiana Bertoni cultivated in Bulgaria. Sains Malays. 2021, 50, 2641. [CrossRef]

43. Gonçalves, V.S.S.; Poejo, J.; Matias, A.A.; Rodríguez-Rojo, S.; Coceroc, M.J.; Duarte, C.M.M. Using different natural origin carriers for development of epigallocatechin gallate (EGCG) solid 2 formulations with improved antioxidant activity by PGSS-drying. RSC Adv. 2016, 6, 67599-67609. [CrossRef]

44. de Jager, T.L.; Cockrell, A.E.; Du Plessis, S.S. Ultraviolet light induced generation of reactive oxygen species. Adv. Exp. Med. Biol. 2017, 996, 15-23. [CrossRef]

45. Nocchi, N.; Duarte, H.M.; Pereira, R.C.; Konno, T.U.P.; Soares, A.R. Effects of UV-B radiation on secondary metabolite production, antioxidant activity, photosynthesis and herbivory interactions in Nymphoides humboldtiana (Menyanthaceae). J. Photochem. Photobiol. B 2020, 212, 112021. [CrossRef] [PubMed]

46. González-Palma, I.; Escalona-Buendía, H.B.; Ponce-Alquicira, E.; Téllez-Téllez, M.; Gupta, V.K.; Díaz-Godínez, G.; Soriano-Santos, J. Evaluation of the antioxidant activity of aqueous and methanol extracts of Pleurotus ostreatus in different growth stages. Front. Microbiol. 2016, 7, 1099. [CrossRef] [PubMed]

47. Ebrahimzadeh, M.A.; Nabavi, S.F.; Nabavi, S.M.; Pourmorad, F. Nitric oxide radical scavenging potential of some Elburz medicinal plants. Afr. J. Biotechnol. 2010, 9, 5212-5217.

48. Palacios-Callender, M.; Quintero, M.; Hollis, V.S.; Springett, R.J.; Moncada, S. Endogenous NO regulates superoxide production at low oxygen concentrations by modifying the redox state of cytochrome c oxidase. Proc. Natl. Acad. Sci. USA 2004, 101, 7630-7635. [CrossRef] [PubMed] 